\title{
Níveis de cobre em amostras de cachaça produzidas na região noroeste do Rio Grande do Sul, Brasil
}

\author{
Levels of copper in "cachaça” samples produced in the Northwest \\ region of Rio Grande do Sul, Brazil
}

Renata Garbin ${ }^{1}$ Stanislau Bogusz Junior² Marco Aurélio Montano $^{3}$

\section{RESUMO}

Com o objetivo de conhecer a qualidade, com destaque para os níveis de cobre, foram analisadas 25 amostras de cachaça artesanal, produzidas e comercializadas em 17 municípios pertencentes às microrregiões Ijuí, Cruz Alta, Santa Rosa e Três Passos, que integram o noroeste do Rio Grande do Sul, Brasil e, compararam-se os valores encontrados, com aqueles estabelecidos pela Legislação. Para as análises, procedeu-se a avaliação dos aspectos gerais das amostras através de observações visuais e olfativas, conforme as recomendações do Ministério da Agricultura para análise de bebidas alcoólicas destiladas. O teor alcoólico foi determinado utilizando-se método densimétrico e os teores de cobre foram determinados através de espectrofotometria de absorção atômica (EAA). Aplicou-se os testes de ANOVA e Tukey. Foram constatados, a partir da análise dos aspectos gerais, que $72 \%$ das amostras apresentaram anormalidades de limpidez. Verificou-se que a Microrregião Três Passos apresentou 42,86\% de suas amostras fora dos limites estabelecidos pela legislação para o teor alcoólico, entretanto os valores médios deste mesmo parâmetro, para todas as amostras das quatro microrregiões, situaram-se dentro do que estabelece a legislação. Quanto aos níveis de cobre, a maior concentração média foi observada na Microrregião Três Passos $\left(10,22 \mathrm{mg} \mathrm{L}^{-1}\right)$ enquanto que na Microrregião Cruz Alta foram observados os menores níveis médios deste metal $\left(2,95 \mathrm{mg} \mathrm{L}^{-1}\right)$. Apenas as microrregiões Ijuí e Três Passos apresentaram diferenças estatisticamente significativas $(P<0,05)$ quanto aos níveis médios de cobre quando comparadas as outras microrregiões. A média regional para os níveis deste metal nas quatro microrregiões foi de $5,71 \mathrm{mg}$ $L^{-1}$, valor acima do limite máximo de $5 \mathrm{mg} \mathrm{L}^{-1}$ permitido pela legislação. Os resultados do presente estudo, apesar de avaliarem apenas alguns dos parâmetros de qualidade para bebidas alcoólicas destiladas, evidenciam a necessidade de adoção de estratégias de apoio tecnológico para capacitação dos produtores, a fim de estimular e ampliar esta atividade agroindustrial importante para a competitividade $e$ a sobrevivência do pequeno e médio produtor rural.

Palavras-chave: cobre, cachaça, destilados, contaminação, níveis.

\section{ABSTRACT}

Whit objective to know the quality, with prominence for the copper levels, 25 samples of craftwork "cachaça” were analyzed, produced and commercialized in 17 cities from four Microregions: Ijuí, Cruz Alta, Santa Rosa and Três Passos, that integrate the northwest of Rio Grande do Sul Brazil and, were compared the found values with those established by the Legislation. For the analyses, was proceeded evaluation from the general aspects of the samples through visual and the sense of smell comments, as the recommendations from the Ministry of Agriculture for liquor analysis. The alcoholic content was determined using densimetric method and the copper content had been determined through espectrofotometric of atomic absorption (EAA). It was applied the tests of ANOVA and Tukey. They had been evidenced, from the analysis of the general aspects, that $72 \%$ of the samples had presented limpidity abnormalities. It was verified that Microregion Três Passos presented $42.86 \%$ of its samples below the legislation to the alcoholic content however the average values for all the samples of the four Microregions. Concerning to the copper levels, the biggest average concentration was observed in Microregion Três Passos (10.22 $\mathrm{mg} \mathrm{L}^{-1}$ ) while in the Cruz Alta region the least average levels of this metal was observed $\left(2.95 \mathrm{mg} \mathrm{L} \mathrm{L}^{-1}\right)$. Only the Microregions Ijuí and Três Passos presented significant estatistics differences according to the copper average levels when compared to the other Microregions. The regional

${ }^{1}$ Curso de Farmácia, Universidade Regional do Noroeste do Rio Grande do Sul (UNIJUI), Ijuí, RS, Brasil.

${ }^{2}$ Departamento de Ciências da Saúde (DCSa), UNIJUI, Rua são Francisco, 501, Bairro São Geraldo, 98700-000, Ijuí, RS, Brasil. Email: stanislau.bogusz@unijui.tche.br. Autor para correspondência.

${ }^{3}$ Coordenadoria de Gestão e Desenvolvimento Tecnológico (CGDT), UNIJUI, Ijuí, RS, Brasil. 
average for the levels of this metal in the four Microregions were of $5.71 \mathrm{mg} \mathrm{L}^{-1}$, value above the maximum limit of $5 \mathrm{mg} \mathrm{\textrm {L } ^ { - }}$ ${ }^{1}$. The results of the present work although was to evaluate only some of the parameters of quality for liquors it became evident of the necessity to adopt technological strategies to support and qualificate the producers in order to stimulate and to extend this important agro-industrial activity for the competitivity and survival of the small agricultural producers.

Key words: copper, “cachaça”, spirits, contamination, levels.

\section{INTRODUÇÃO}

Segundo a Legislação Brasileira, Decreto n. 4851, de 02/10/2003, Art. 92, o termo cachaça referese a: "denominação típica e exclusiva da aguardente de cana produzida no Brasil, com graduação alcoólica de 38 a $48 \%$ em volume a $20^{\circ} \mathrm{C}$, obtida pela destilação do mosto fermentado de cana-de-açúcar com características sensoriais peculiares”(BRASIL, 2003).

Tal como o vinho na Itália, o uísque na Escócia, a cerveja na Alemanha, o Brasil vem se destacando na produção de cachaça. Esta, de líquido marginal, foi elevada ao posto de bebida nobre, símbolo nacional, e terceiro destilado mais consumido no mundo, atrás apenas da vodca e do soju (bebida asiática à base de sorgo). O Decreto n ${ }^{\circ} 4062$ de 21/12/ 2001 e a Lei da Propriedade Industrial n ${ }^{\circ}$ 9279/96 definem as expressões “Cachaça”, "Brasil” e "Cachaça do Brasil” como, produto de qualidade única tendo em vista as suas características naturais, e indicações geográficas brasileiras (BRASIL, 2001; BRASIL 1996; COPELLO, 2004).

O processo produtivo da cachaça pode ser resumido pelos seguintes estágios: preparação da matéria prima (corte da cana-de-açúcar, separação das suas folhagens; transporte e armazenamento), seguido da extração do caldo e sua fermentação. O resultado desta fermentação é levado à destilação em alambique de cobre, a partir do qual se obtém a cachaça. Esta pode ainda ser envelhecida em tonel de madeira para finalmente ser engarrafada, distribuída e comercializada (LIMA NETO \& FRANCO, 1994).

A região noroeste do Rio Grande do Sul possui uma significativa quantidade de produtores artesanais de cachaça que utilizam alambiques de cobre para obterem o destilado alcoólico de cana-de-açúcar. Entretanto, é de conhecimento comum que muitos leigos se encontram à frente das unidades produtoras executando o processo, muitas vezes, de maneira empírica e rudimentar, baseados no senso comum ou em informações que passam de pai para filho. Esta forma de produção empírica e artesanal pode fazer com que o produto que chega ao consumidor contenha níveis de cobre acima do estabelecido pela legislação.

O cobre é considerado um metal essencial em níveis traços, sendo que o Food Nutritional Board (FBN) estabeleceu para este metal o RDA (Recommended Dietary Alowance) de 1,5 a 3,0mg por dia para adultos (RDA, 1998). O metal atua como cofator de diversas enzimas celulares, como a catalase, citocromoxidase, dopamina- $\beta$-hidroxilase e peroxidases. As manifestacões decorrentes da deficiência do metal incluem disfunção cardíaca, aumento de lipoproteínas de baixa densidade e elevação da fração de colesterol de alta densidade, diminuição de metionina, encefalinas leucínicas, cobrezinco superóxido dismutase eritrocitária e diminuição da depuração da glicose (PEDROZO \& LIMA, 2001).

Distúrbios da concentração normal do cobre solúvel no organismo podem provocar hiper ou hipocupremia. A mais conhecida enfermidade decorrente desta descompensação é a Doença de Wilson, uma degeneração hepato-lenticular que leva a destruição do fígado e do tecido nervoso. Além disso, epilepsia, melanoma, esclerose, aceruloplasminemia, doença de Alzheimer e a artrite reumatóide, são patologias provavelmente relacionadas com o metabolismo do Cobre, porém, ainda são motivos de controvérsias e discussões (AZEVEDO et al., 2003).

A entrada do cobre na cachaça ocorre na etapa de destilação, uma vez que o metal constituinte do equipamento, quando exposto ao ar úmido contendo gás carbônico lentamente se oxida, ficando coberto por uma camada esverdeada, chamada de “azinhavre”, composta por $\left[\mathrm{CuCO}_{3} \mathrm{Cu}(\mathrm{OH})_{2}\right]$. Esta camada é então dissolvida pelos vapores alcoólicos ácidos, gerados durante o processo de destilação da cachaça, o que acaba contaminando o produto (BOZA \& HORII, 2000).

Apesar de todos estes dados sobre os efeitos tóxicos do excesso do metal sobre a saúde, o emprego de destiladores de cobre no processo de obtenção da cachaça é freqüente, pois, muitos pesquisadores atribuem ao metal o papel de catalisador durante a destilação, além de eliminar determinados odores desagradáveis (sulfetos) (NASCIMENTO et. al, 1998; BOZA \& HORII, 2000).

A legislação Brasileira Decreto no 2314 de 04/09/1997 estabelece o limite máximo para os teores de cobre em aguardente em $5 \mathrm{mg} \mathrm{L}^{-1}$ de produto (BRASIL, 1997). Apesar de não ocorrerem barreiras fiscais no mercado interno, para o excesso de cobre, quando se trata de mercado internacional a situação se inverte, há países que não toleram mais que $2 \mathrm{mg} \mathrm{L}^{-1} \mathrm{de}$ 
cobre nos destilados alcoólicos, fator este considerado um entrave para a exportação da bebida (AZEVEDO et. al, 2003).

Com base no exposto, realizou-se a presente pesquisa que objetivou conhecer a realidade da qualidade da cachaça produzida na região noroeste do Rio Grande do Sul, por meio de análises físicoquímicas, em amostras provenientes de diferentes municípios da região, com destaque para os teores de cobre, uma vez que são empregados destiladores deste material no processo de obtenção da cachaça.

\section{MATERIAL E MÉTODOS}

No período de junho a agosto de 2004, foram coletadas vinte e cinco amostras de cachaça artesanal, provenientes de quatro microrregiões que integram a região noroeste do Rio Grande do Sul: Microrregião Ijuí (municípios de Ajuricaba, Augusto Pestana, Condor, Ijuí, Panambi e Santo Augusto), Microrregião Três Passos (municípios de Bom Progresso, Campo Novo, Horizontina e Três Passos), Microrregião Santa Rosa (municípios de Catuípe, Giruá, Santa Rosa e Santo Ângelo) e Microrregião Cruz Alta (municípios de Colorado, Cruz Alta e Jóia). Todas as amostras foram adquiridas no comércio local destes diferentes municípios. As amostras coletadas foram devidamente identificadas e armazenadas até o momento das análises. As análises físico-químicas seguiram as técnicas do Ministério da Agricultura quanto à análise de bebidas destiladas. Seguindo estas técnicas, avaliaram-se as características gerais da amostra (aspecto, coloração, limpidez, vazamentos e estufamentos) através de exames visuais; teor alcoólico (método densimétrico) e teor de cobre por meio de medidas espectrofotométricas de absorção atômica, em espectrofotômetro de absorção atômica com chama de ar/acetileno oxidante, GILSON modelo GBC 932 AA, com corretor de deutério, utilizando lâmpada de cátodo oco de cobre (325nm), abertura de fenda de 0,7 nm. Empregaram-se padrões cobre Merck $\left(\mathrm{CuCl}_{2}\right)$ nas concentrações 0,$5 ; 1,0 ; 2,0 ; 3,0 ; 4,0$ e $5,0 \mathrm{mg} \mathrm{L}^{-1}$, preparados em solução hidroalcoólica $40 \%$ v/v a $20^{\circ} \mathrm{C}$. Para as análises estatísticas aplicaram-se os testes de ANOVAe Tukey, utilizando-se o software SPSS 12.0.

\section{RESULTADOS E DISCUSSÃO}

Os resultados das análises das características gerais das amostras (aspecto, coloração, limpidez, vazamentos e estufamentos) revelaram que $72 \%$ das mesmas apresentavam anormalidades de limpidez.
Tais resultados sugerem falta de cuidados higiênicos, bem como falta de tecnologias adequadas de produção. Estes problemas poderiam ser facilmente eliminados pelo emprego de simples práticas higiênicas no processo produtivo, como, por exemplo, o emprego de filtragem antes do engarrafamento, utilizando celulose, algodão ou resina neutra (SEBRAE-MG, 2001). As demais características gerais analisadas não foram indicativo de anormalidades para nenhuma das amostras.

Na tabela 1, podem-se observar as freqüências, os valores médios e os intervalos de concentração dos teores alcoólicos encontrados nas amostras de cachaça artesanal provenientes de quatro microrregiões do noroeste do Rio Grande do Sul. A Microrregião Ijuí foi a que apresentou uma menor quantidade de amostras $(11,1 \%)$ com teores de álcool fora do que estabelece a legislação (mínimo de 38 e um máximo de $48 \%$ de álcool em vol. a $20^{\circ} \mathrm{C}$ ), se comparada com as demais microrregiões. Enquanto que, a Microrregião Três Passos apresentou a maior quantidade de amostras (42,86\%) com teores alcoólicos fora do que preconiza a legislação.

Quanto aos valores médios de teor alcoólico, a Microrregião Ijuí apresentou valores de $42,64 \%$ vol. a $20^{\circ} \mathrm{C}$ enquanto que as microrregiões Três Passos, Santa Rosa e Cruz Alta apresentaram teores alcoólicos de 38,50, 39,60 e 38,23\% vol. a $20^{\circ} \mathrm{C}$, respectivamente. Destaca-se que os valores médios para todas as amostras das quatro microrregiões encontram-se dentro do que estabelece a legislação. Não foram observadas diferenças estatísticas significativas entre os teores alcoólicos das amostras de cachaça artesanal e as microrregiões de onde foram obtidas.

A média regional quanto ao teor alcoólico permaneceu dentro dos limites legais (40, $17 \pm 3,95 \%$ em volume a $20^{\circ} \mathrm{C}$ ), embora os intervalos de concentração tenham variado entre o mínimo de 31,10 e o máximo de $47,70 \%$ em volume a $20^{\circ} \mathrm{C}$. Estes valores, inferiores ao que determina a legislação, indicam uma provável adição acentuada de água ao destilado no momento da padronização da cachaça, visando um melhor rendimento do produto.

As análises dos níveis de cobre (Tabela 2) revelaram que $11,11 \%$ das amostras da Microrregião Ijuí apresentaram níveis para este metal acima do limite máximo permitido pela legislação $\left(5 \mathrm{mg} \mathrm{L}^{-1}\right)$. Em contrapartida, as microrregiões Cruz Alta, Santa Rosa e Três Passos apresentaram respectivamente 25,00; 57,14 e 60,00\% de suas amostras acima deste limite. KÜCHLER \& SILVA (1999) analisando amostras de destilado de cana-de-açúcar, provenientes dos estados 
Tabela 1 - Freqüência de amostras fora dos parâmetros legais, valores médios \pm desvio padrão e intervalo de concentração do Teor Alcoólico em amostras de cachaça artesanal pertencentes a quatro microrregiões integrantes da região noroeste do Rio Grande do Sul.

\begin{tabular}{|c|c|c|c|}
\hline \multirow{2}{*}{ Microrregião } & \multicolumn{3}{|c|}{ Teor alcoólico (\% vol. a 20 C) } \\
\hline & $\begin{array}{l}\text { Freqüência de amostras fora } \\
\text { dos parâmetros legais (\%) }\end{array}$ & Média \pm DP & Intervalo de concentração \\
\hline Ijuí (N = 9) & 11,11 & $42,64 \pm 3,55^{a}$ & $37,30-47,70$ \\
\hline Cruz Alta $(\mathrm{N}=4)$ & 40,0 & $38,23 \pm 6,19^{a}$ & $31,10-45,70$ \\
\hline Santa Rosa $(\mathrm{N}=5)$ & 20,0 & $39,60 \pm 3,42^{\mathrm{a}}$ & $34,60-43,20$ \\
\hline Três Passos (N = 7) & 42,86 & $38,50 \pm 2,05^{\mathrm{a}}$ & $35,70-40,60$ \\
\hline Média regional & & $40,17 \pm 3,95$ & \\
\hline
\end{tabular}

Letras diferentes indicam diferenças significativas, pelo teste de Tukey em nível de 5\% de probabilidade de erro.

do Rio de Janeiro, São Paulo, Pernambuco e Ceará, encontraram níveis de cobre acima do permitido pela legislação em $12 \%$ destas amostras. Em um estudo similar realizado em Minas Gerais AZEVEDO et al. (2003), encontraram níveis de cobre acima do permitido em apenas 6,7\% das amostras analisadas. Estes resultados revelam que as amostras das microrregiões Cruz Alta, Santa Rosa e Três Passos apresentaram níveis de cobre acima daqueles encontrados para outros estados brasileiros. Estes dados são conclusivos para afirmar que estas microrregiões necessitam de maior atenção, por parte dos órgãos competentes, no tocante a uma maior assistência técnica e melhorias na tecnologia de produção.

Quanto às concentrações médias de cobre, as amostras provenientes da Microrregião Cruz Alta apresentaram os menores valores para este metal (2,95 $\left.\mathrm{mg} \mathrm{L}^{-1}\right)$. As concentrações médias para as demais microrregiões seguiram a seguinte ordem: Ijuí (3,32mg $\left.\mathrm{L}^{-1}\right)$, Santa Rosa (5,93mg L $\left.{ }^{-1}\right)$ e Três Passos $(10,22 \mathrm{mg}$ $\left.\mathrm{L}^{-1}\right)$. Destaca-se que os valores médios de cobre para as amostras das microrregiões Santa Rosa e Três Passos excederam o limite máximo estabelecido pela legislação brasileira ( $\left.5 \mathrm{mg} \mathrm{L}^{-1}\right)$. Embora as amostras das microrregiões Cruz Alta e Ijuí não tenham excedido este limiar, encontram-se acima do máximo permitido para exportação (2mg L ${ }^{-1}$ ) (LIMA NETO \& FRANCO, 1994). Verificou-se uma diferença significativa entre as concentrações de cobre das microrregiões Ijuí e Três Passos, o que indica grandes disparidades quanto à falta de cuidados higiênicos e de conhecimentos técnicos de produção entre estas microrregiões como pode ser observado na tabela 1.

Os valores elevados de cobre nas amostras das microrregiões Três Passos e Santa Rosa sugerem os mesmos problemas apontados nas análises de teor de álcool, ou seja, falta de higiene e tecnologia de produção. Segundo NASCIMENTO et al. (1998) e CARDOSO et al. (2000), a higiene do alambique no momento da destilação é imprescindível para evitar contaminações com cobre. Para isso, CARDOSO, et al. (2000) recomendam uma adequada limpeza do destilador, antes de se iniciar uma nova alambicada, realizando uma pré-destilação com solução ácida ou suco de limão e água na proporção de 5:100 L. Segundo estes autores, este processo seria suficiente para remover o azinhavre do alambique,

Tabela 2 - Freqüência de amostras fora dos parâmetros legais, valores médios \pm desvio padrão e intervalo de concentração dos níveis de Cobre em amostras de cachaça artesanal pertencentes a quatro microrregiões integrantes da região noroeste do Rio Grande do Sul.

\begin{tabular}{lccc}
\hline & & Cobre (mg L $\left.{ }^{-1}\right)$ \\
\cline { 2 - 4 } Microrregião & $\begin{array}{c}\text { Freqüência de amostras fora dos } \\
\text { parâmetros legais (\%) }\end{array}$ & Média \pm DP & Intervalo de concentração \\
\hline Ijuí $(\mathrm{N}=9)$ & 11,11 & $3,32 \pm 3,54^{\text {ab }}$ & $0,19-11,65$ \\
Cruz Alta $(\mathrm{N}=4)$ & 25,0 & $2,95 \pm 6,78^{\mathrm{b}}$ & $0,92-5,03$ \\
Santa Rosa $(\mathrm{N}=5)$ & 57,14 & $5,93 \pm 14,85^{\mathrm{b}}$ & $2,61-9,85$ \\
Três Passos $(\mathrm{N}=7)$ & 60,0 & $10,22 \pm 7,08^{\mathrm{cb}}$ & $2,99-22,30$ \\
Média regional & & $5,71 \pm 5,29$ & \\
\hline
\end{tabular}

Letras diferentes indicam diferenças significativas, pelo teste de Tukey em nível de 5\% de probabilidade de erro.

Ciência Rural, v.35, n.6, nov-dez, 2005. 
principalmente aquele existente no interior da serpentina de condensação dos vapores hidroalcoólicos, local de maior contaminação da cachaça pelo cobre. Além disso, SARGENTELLI et al. (1996) recomendam que seja realizada, uma assepsia criteriosa dos alambiques após o término diário do procedimento de alambicagem, o que contribui para a redução considerável dos problemas da presença de excesso cobre nas aguardentes. Outra prática citada por AZEVEDO et al. (2003), para se evitar os níveis elevados de cobre nos destilados, é manter o equipamento de destilação cheio de água no período de entressafra, de modo a impedir a oxidação do cobre e a formação do azinhavre.

Para aquelas amostras que já se encontram com níveis elevados de cobre, BIZELLI et al. (2000) recomendam alternativas como a bidestilação para a redução dos teores deste metal nas mesmas.

\section{CONCLUSÃO}

As amostras de cachaça analisadas revelaram problemas de qualidade nos aspectos de limpidez, teor alcoólico fora do que preconiza a legislação, e níveis de cobre, principalmente na Microrregião Três Passos que apresentou os maiores problemas de teor alcoólico e níveis de cobre (42,86\% e $60,00 \%$ das amostras fora destes parâmetros legais respectivamente). Entretanto, a média regional para o teor alcoólico permaneceu dentro dos limites legais, e a media regional para os níveis de cobre situaram-se acima deste parâmetro.

Apesar de serem avaliados apenas alguns dos parâmetros qualitativos e quantitativos da cachaça, os resultados das análises físico-químicas apresentados constituem importante instrumento para o monitoramento da qualidade, principalmente no que diz respeito aos níveis de cobre. Destaca-se que este é o primeiro trabalho que apresenta dados sobre a cachaça artesanal produzida na região noroeste do Rio Grande do Sul. Sugere-se, portanto, a ampliação do presente estudo, com a finalidade de se conhecer os demais parâmetros indicativos da qualidade da mesma.

\section{AGRADECIMENTOS} primeiro autor.

Trabalho de Conclusão do Curso de Farmácia, do

\section{REFERÊNCIAS}

AZEVEDO, S.M. et al. Levantamento da contaminação por cobre nas aguardentes de cana-de-açúcar produzidas em Minas
Gerais. Ciência e Agrotecnologia, Lavras. v.27, n.3, p.618624, 2003.

BIZELLI, L.C. et al. Dupla destilação da aguardente de cana: teores de acidez total e de cobre. Scientia Agrícola, Piracicaba, v.57, n.4, p.623-627, 2000.

BOZA, Y.; HORII, J. Influência do grau alcoólico e da acidez do destilado sobre o teor de cobre na aguardente. Ciência e Tecnologia de Alimentos, Campinas. v.20, n.3, p.279-284, 2000.

BRASIL. Ministério da Agricultura, Pecuária e Abastecimento. Decreto no․ 2314, de 04 de setembro de 1997. Publicado no Diário Oficial da União de 05/09/1997, Brasília, seção 1, p.19549.

BRASIL. Decreto no 4062, de 21 de dezembro de 2001. Publicado no Diário Oficial da União de 26/12/2001. Capturado em 1/10/2004. Online. Disponível na internet: h t t p : / / o 4 j.agricultura.gov.br/agrolegis / do / consultaLei?op=viewTextual\&codigo $=1014$.

BRASIL. Ministério da Agricultura, Pecuária e Abastecimento. Decreto no. 4851 de 02 de outubro de 2003. Publicado no Diário Oficial da União de 03/10/2003, Brasília, seção 1, p.6.

BRASIL. Lei no 9279 de 14 de Maio de 1996. Publicado no Diário Oficial da União de 15/05/1996. Capturado em $1 /$ 10/2004. Online. Disponível na internet: http:// www.peduti.com.br/Legislacao/marcas-1.asp.

CARDOSO, M. das G. Análises físico-químicas de aguardente. In: _____. Produção artesanal de aguardente. Lavras: UFLA/FAEPE, 2000. p.61-73.

COPELlO, M. A mais brasileira das bebidas. Gazeta Mercantil. Caderno de Fim de semana, 30 de novembro de 2004.

KÜCHLER, I.L.; SILVA, F.A.M. Método potenciométrico para determinação de cobre em cachaça. Química Nova, São Paulo, v.22, n.3, p.339-341, 1999.

LIMA NETO, B.S.; FRANCO, D.W. A aguardente e o controle químico de sua qualidade. Engarrafador Moderno, São Caetano do Sul, v.4, n.33, p.5-8, 1994.

NASCIMENTO, F.R. et al. Influência do material do alambique na composição química das aguardentes de canade-açúcar. Química Nova, São Paulo, v.21, n.6, p.735739, 1998.

PEDROZO, M.F.M.; LIMA, V.I. Ecotoxicologia do cobre e seus compostos. Salvador-BA: CRA, 2001.

RECOMMENDED DIETARY ALOWANCES. Subcommitte on the Tenth Edition of RDAs. Washington: National Academic, 1998. Cap.10, p.195-246.

SARGENTELLI, V. et al. Aspectos do metabolismo do cobre no homem. Química Nova, São Paulo, v.19, n.3, p.290293, 1996.

SEBRAE-MG. Diagnóstico da cachaça de Minas Gerais, Belo Horizonte, julho de 2001. Capturado em 26 nov. 2004. Online. Disponível na Internet: http://www.sebraemg.com.br/ agronegocios/Cachaca/Cacha\%E7a\%20MG.pdf 